\title{
Internal jugular vein phlebectasia
}

\author{
T A G Fernando ${ }^{1}$ and D S C Perera ${ }^{2}$
}

(Index words: Signs, investigation, management)

\section{Introduction}

Internal jugular vein (IJV) phlebectasia is a rare form of congenital venous anomaly. Less than 50 cases have been reported in the literature world-wide. In the majority of cases the lesion was in boys and on the right side. It is a fusiform dilation of the vein without any apparent obstruction, and is believed to be due to congenital thinning of the vessel wall. It can mimic an external laryngocele.

\section{Case report}

A 8-year old schoolboy was referred to our clinic with a history of a distensible lump appearing in the anterior triangle of the right side of the neck with singing and blowing his mouth against a closed glottis. It completely disappeared at rest. It was first noticed at the age of three years. He was otherwise asymptomatic. On examination a soft compressible lump with ill-defined margins was felt anterior to the middle part of the right sternomastoid muscle when he performed Valsalva manoeuvre. There were no visible or palpable pulsations or murmurs over the lump.

Neck xrays performed with Valsalva manoeuvre failed to show an air filled sac, and laryngocele was excluded. Ultrasonography showed a fluid filled unilocular sac in continuity with the IJV measuring $4.2 \times 3.1 \times 1.7 \mathrm{~cm}$. (Figure). The IJV above and below the lesion appeared normal. Carotid arteries and the opposite IJV were normal. Doppler studies showed a venous flow pattern within it. No cardiac or major vessel abnormalities were seen in the $2 \mathrm{D}$ echocardiography and the chest xray was normal.

\section{Discussion}

This rare form of clinically silent venous anomaly is generally noticed in the 3 to 12 year age group. The main reason to seek medical attention is parental concern. External laryngocele, pharyngocele and superior mediastinal cysts are the main differential diagnoses of this condition. Although they are noticed few years after birth, these are believed to be congenital anomalies of unknown aetiology. In excised specimens, no significant pathology was seen except for the thinning of the musculature of the vessel wall (1).

Ultrasonography, Doppler studies, and spiral computerised tomography are the methods used to confirm this condition (2). Invasive venographic studies are no longer required.

No significant morbidity is reported in the literature, and patients with IJV phlebectasia should be managed conservatively. In the past excision was the recommended treatment $(2,3)$.
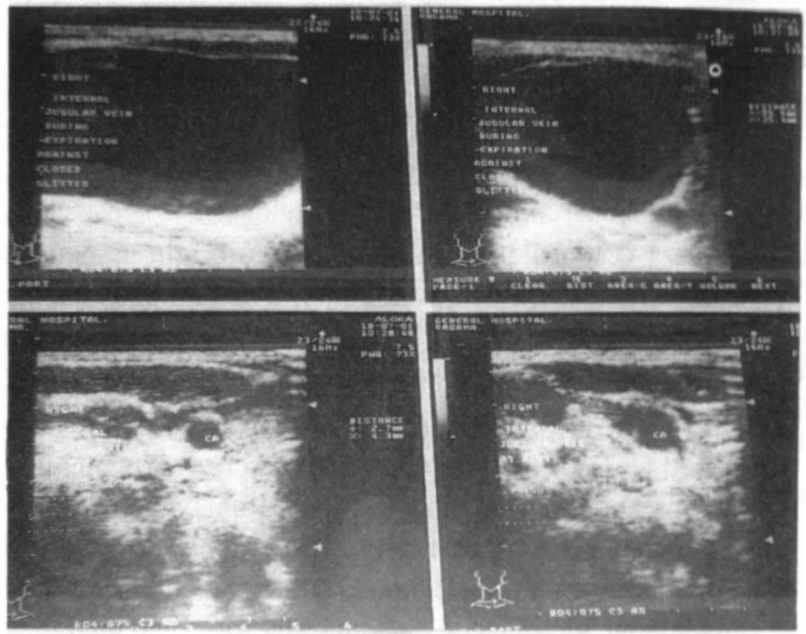

Figure. Ultrasonographic pictures of the neck showing distension of the right internal jugular vein in horizontal and longitudinal planes with Valsalva manoeuvre (top row) and at rest (bottom row).

\section{Acknowledgement}

We thank Dr V Gnananandan, Radiologist, Colombo North Teaching Hospital, Ragama, for his assistance.

\section{References}

1. Bowlder DA, Singh SD. Internal jugular phlebectasia. International Journal of Paediatric Otolaryngology 1986; 12: 165 71.

2. Al Dousary S. Internal jugular phlebectasia. International Journal of Paediatric Otolaryngology 1997; 38: 273-80.

3. Mickelson SA, Spickler E, Roberts K. Management of internal jugular vein phlebectasia. Otolaryngology and Head and Neck Surgery 1995; 112: 473-75.

${ }^{1}$ Senior Registrar in Otolaryngology, and ${ }^{2}$ ENT Surgeon, Colombo North Teaching Hospital, Ragama. (Received 22 September 2001, accepted 19 December 2001. Corresponding author DSCP, email: shantha2@sltnet.lk, telephone +941959261) 